\title{
Taguchi Analysis of Bonded Single-Lap Joint in Hemp Fiber Composite
}

\author{
${ }^{1}$ Rupesh Lokhande, ${ }^{2}$ Abhijeet Deshpande and ${ }^{3}$ Ashok Mache \\ 1, 2, 3 Department of Mechanical Engineering, Vishwakarma Institute of Information Technology, Kondhwa \\ (Bk), Pune-411048, India \\ Irupeshlokhande15@gmail.com
}

\begin{abstract}
The adhesively bonded joints in composite structures are widely used in aerospace and automobile fields. Hemp epoxy composites are better alternative due to its lower specific gravity and higher toughness. . The joining process is inevitable in the application of such composites. The mechanical behaviour of such joints depends on the strength of the composite, adhesive strength and adhesion phenomenon between substrate and adhesive. The influence of overlap length, adhesive layer thickness and cure temperature on the performance of adhesive joints investigated experimentally. The influence of these parameters on the static behaviour of the joint was studied using design of experiment approach. L9 orthogonal array was used for experimental design. It was found that cure temperature of adhesive predominantly governs joint behaviour followed by adhesive layer thickness and overlap length. To obtain joint strength in the working limits, an empirical relationship between governing parameters and response was developed. Through the analysis it was observed that optimum strength of bonded joint was obtained with overlap length of $25 \mathrm{~mm}$, adhesive layer thickness of $0.5 \mathrm{~mm}$ and cure temperature of $50^{\circ} \mathrm{C}$.
\end{abstract}

Index Terms- Taguchi Methods, natural fibers, structural adhesives, bonded joints

\section{INTRODUCTION}

Bonded joints have an ability to join materials with irregular or complex shapes with good aesthetics and taking due care of the shape the components. These joint can be a permanent or temporary depending on application and type of adhesive used. The bonded joint produces lower stress concentration as compared to bolted, riveted and welded joints. The stress distribution in bonded joints found out to be uniform as compared to other joints. However, parts joined with adhesive can induce residual stresses due different thermal expansion coefficients as some strong adhesive generates heat while curing. In addition, the degradation of joint may occur with the time.

It was observed that generally the failure in bonded joints initiates at the adhesive layer. The failure mode analysis carried out by researchers showed that crack initiates at free edges of bond line leading to failure under tensile loading [1-3]. However, it was also found that adherent delamination failure occurs due to increased overlap length. The stock break failure was common with increased overlap length. Rahman [5] investigated that in adhesively bonded joints of metal substrates, failure happens near the adhesive-substrate interface due to high bending moment at the substrate. Khalili [6] investigated the strength of adhesively bonded single lap joint subjected to tensile, bending, impact and fatigue loads. They used glassreinforced composites as adherend and epoxy reinforced with micro glass powder, unidirectional and chopped glass fiber, as adhesive. They varied the orientation of fibers in adhesive region as $0^{0}, 45^{\circ}, 90^{\circ}$ and maintained volume fraction of glass fibers to $30 \%$. They found that such reinforcement increases strength of joint from 11.89 $\mathrm{MPa}$ to $17.41 \mathrm{MPa}$ but failure mode varied from cohesive failure to adherend failure. Taib [7] reported that increasing adhesive thickness to $2 \mathrm{~mm}$ decreases the failure load by $63 \%$. This happens due to voids being 
incorporated in adhesive region as adhesive layer thickness increases. This leads to decrease the joint strength. The FEA study also predicts the joint strength and failure location similar to the experimental results considering nonlinear nature of problem. Campilho [8] studied tensile fracture toughness of adhesive joints in natural fiber composites. They had used ductile polyurethane adhesive and jute-epoxy adherends in order to carry out that work. Conventional methods used to obtain tensile fracture toughness for the co-cured specimens, while for the adhesively bonded joints; the $J$-integral was selected. They found that fracture toughness increases from initiation in co-cured specimens due to fiber bridging between the adherends while the crack grows. Results showed that bonded joint was tougher than co-cured joint. In the study, they compared two bonding methods and provided tensile fracture data for the strength prediction of joints in natural fiber composites. Mahoney [9] studied behavior of adhesively bonded composite joint by Taguchi analysis in order to present order of most influencing parameter to determine ultimate failure load. They found that bonding strength was dependent upon strength of adhesive, composite-adhesive interfacial adhesion and strength of adherend. Also finite element model had calibrated against obtained experimental results and from that prediction of strength obtained by numerical results found to be in acceptable condition. In Taguchi analysis, they found that adhesive strength, interface fracture energy, and adhesive ductility were main parameter that primarily affects failure loads.

This work was focused on investigating strength of adhesively bonded hemp epoxy composites. The experiments were carried out to investigate influence of variation in overlap length, adhesive layer (bondline) thickness and cure temperature of adhesive on tensile strength of joint. Design of experiment approach was adopted for design experiments. A parametric study was carried out for these joint parameters in order to determine its effect on the ultimate failure load. For this study, a single lap shear joint was selected, as it is commonly used bonded joint.

\section{MATERIALS AND MANUFACTURING}

The adherends used in this study consist of hemp-epoxy composite, with woven hemp fibre as reinforcement. The hemp was selected due to its appealing strength and toughness properties as a reinforcement material (50\% of glass fibres). It has the higher stiffness than any other natural fibres such as jute, kenaf [11]. More importantly, the specific flexural strength of hemp composite is higher than that of glass fibre composites. The tensile modulus of hemp composites is equal to the tensile modulus of glass fibre composites. This makes hemp as a better replacement for glass fibre composites. The typical properties of hemp are: density of 1.3$1.5 \mathrm{~g} / \mathrm{cm}^{3}$, elongation at failure $1.6 \%$, the tensile strength of $550-900 \mathrm{MPa}$ and tensile modulus of $70 \mathrm{GPa}$. Epoxy was selected as matrix material due to its better mechanical (strength, stiffness, toughness). It also possesses superior wetting characteristics with natural fibres. This improves chemical stability of such composites with excellent mechanical properties. The matrix material was of Tuff-Tite Resin and Tuff-Tite Hardener epoxy system. The mixture was prepared by manual mixing of two components. The matrix properties are: density of $1.08 \mathrm{~g} / \mathrm{cm}^{3}$ and tensile strength of $15 \mathrm{MPa}$. The adhesive used for bonding was Fevitite Standard structural grade. It has the density of $1.15 \mathrm{~g} / \mathrm{cc}$ and achieves bond strength up to $15 \mathrm{MPa}$ at room temperature. It has excellent resistance to water, salt spray, and most organic fluids and presents high mechanical performance up to $120^{\circ} \mathrm{C}$.

The specimens were made of hemp-epoxy composite plates with six stacked woven plies. Hand lay-up technique has accounted to manufacture the laminate. The laminates are allowed to cure for 24 hours under compression in compression moulding machine. It was done to evenly spread the matrix, remove any air bubble and wrinkles from the laminate. This also ensures good adhesion between the layers. Uniform thickness of the laminate $3.5 \mathrm{~mm}$ was maintained using spacers. For adhesion to take place it was necessary for wetting to occur between the adhesive and the adherend, it relates the spreading of liquid on solid surface. It was achieved by proper surface preparation. The quality of adhesively bonded joints was greatly influenced by surface preparation of the adherend. To prepare good bond strength and durability, production 
of a roughened surface, cleaned of contaminants (particularly any chemicals, grease, and dust resulting due to exposure or after the composite fabrication process), was required. The roughened surface was obtained by grinding it with 240 -grit water paper followed by cleaning with acetone.

\section{EXPERIMENTAL DETAILS}

\subsection{Specimen Configuration}

Specimens were made according to ASTM D5868-01. For preparing single lap joint configuration, strips of the laminate were cut by water jet and bonded with adhesive. The width of the strips used was $25 \mathrm{~mm}$ and the length was maintained as $100 \mathrm{~mm}$. Post curing was required to ensure the polymerization cycle of the matrix and adhesive in order to improve the mechanical properties of bonded joints. Therefore, specimens were kept at room temperature for 3-4 days. The average thickness of adherend was maintained as $3.5 \mathrm{~mm}$. The geometry of the single lap joint is as shown in figure 1.

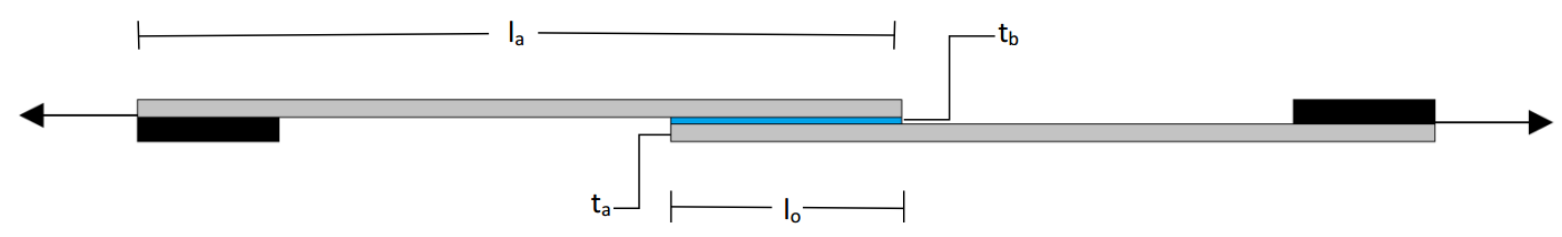

\section{Figure 1 Geometry of the specimen}

Three parameters were selected for the experimentation such as: overlap length, bondline thickness and curing temperature. From the literature, we was observed that overlap length of 20 $\mathrm{mm}$ to $30 \mathrm{~mm}$ was optimum [2, 4, and 6], whereas the bondline thickness ranging from $0.2 \mathrm{~mm}$ to $0.8 \mathrm{~mm}$ gives better joint strength $[12,13$, and 14]. The technical data sheet available for Fevitite Standard adhesive depicts that cure temperature between $30^{\circ} \mathrm{C}$ to $70^{\circ} \mathrm{C}$ will give best suited joint strength. Hence, variation in curing temperature selected was from $30^{\circ} \mathrm{C}$ to $70^{\circ} \mathrm{C}$. Selected parameters were distributed with three levels. The parameter ranges selected for experimentation are as shown in table 3.1.

Table 3.1 Joint Parameter Ranges

\begin{tabular}{|l|l|l|l|l|}
\hline Sr. No. & Parameter & \multicolumn{3}{|l|}{ Parameter Ranges Values } \\
\hline 1 & Overlap Length $(\mathrm{mm})$ & 20 & 25 & 30 \\
\hline 2 & $\begin{array}{l}\text { Bondline Thickness } \\
(\mathrm{mm})\end{array}$ & 0.3 & 0.5 & 0.7 \\
\hline 3 & Cure Temperature $\left({ }^{0} \mathrm{C}\right)$ & 30 & 50 & 70 \\
\hline
\end{tabular}

\subsection{Test Procedure}

The tensile shear tests were carried out on servo hydraulic universal testing machine TUE-C 600 with 600-Ton capacity. The test setup had incremental static loading and recorded elongation by automated recording system. A controlled loading rate of $3 \mathrm{~mm} / \mathrm{min}$ was applied as mentioned in ASTM D5868-01. The specimens were loaded in quasi-static tension in the fibre direction.

\subsection{Taguchi Methods}

In the Taguchi design method, process variables usually classified into control, noise, and signal factors. Control factors are any design parameters of a system that engineers can specify by 
nominal values and for maintaining cost effectively. Noise factors cause variability in terms of practical or economic reasons, leading to performance deterioration. A signal factor was sent into a system in response to the intent of the user. It was adjustable so that an engineered system can generate a dynamic spectrum of the output responses to enable the evaluation of the functionality of the system. Taguchi method is a powerful design of experiments (DOE) tool for engineering optimization of a process. For the experimentation L9 orthogonal array was selected. The $\mathrm{S} / \mathrm{N}$ ratio characteristics can be divided into three categories when characteristics are continuous:

i. Smaller the better characteristics

$\frac{S}{N}=-10 \log \frac{1}{n} \sum y^{2}$

ii. Larger the better characteristics

$\frac{S}{N}=-10 \log \frac{1}{n} \sum \frac{1}{y^{2}}$

iii. Nominal the best characteristics

$\frac{S}{N}=10 \log \frac{1}{n} \sum \frac{\bar{y}}{S y^{2}}$

The present work was focused on improving the tensile strength of the adhesively bonded joints. The influence of selected parameters on tensile strength of bonded joint was investigated. Three variable parameters with three different levels were selected for study, whereas tensile strength of bonded joint was selected as response. For the present work larger the better S/N ratio was selected.

\section{RESULTS AND DISCUSSION}

The objective of this experiment was to optimize joint parameters to get highest joint strength. For that higher is better characteristics were used. Analysis was as shown in table 4.1 for $\mathrm{S} / \mathrm{N}$ ratio. The $\mathrm{S} / \mathrm{N}$ ratio is highest for joint strength of $5.184 \mathrm{MPa}$.

Table 4.1 Response table for signal to noise ratios higher is better

\begin{tabular}{|l|l|l|l|l|}
\hline $\begin{array}{l}\text { Overlap } \\
\text { Length } \\
(\mathrm{mm})\end{array}$ & $\begin{array}{l}\text { Adhesive } \\
\text { Thickness } \\
(\mathrm{mm})\end{array}$ & $\begin{array}{l}\text { Cure } \\
\text { Temp. } \\
\left({ }^{0} \mathrm{C}\right)\end{array}$ & $\begin{array}{l}\text { Joint } \\
\text { Strength } \\
(\mathrm{MPa})\end{array}$ & SN Ratio \\
\hline 20 & 0.3 & 30 & 3.66 & 11.26962 \\
\hline 20 & 0.5 & 50 & 4.44 & 12.88813 \\
\hline 20 & 0.7 & 70 & 5.07 & 14.0997 \\
\hline 25 & 0.3 & 50 & 4.825 & 13.6696 \\
\hline 25 & 0.5 & 70 & 5.184 & 14.23853 \\
\hline 25 & 0.7 & 30 & 3.432 & 10.56732 \\
\hline 30 & 0.3 & 70 & 3.58 & 11.06749 \\
\hline 30 & 0.5 & 30 & 4.46 & 12.98015 \\
\hline 30 & 0.7 & 50 & 4.62 & 13.29064 \\
\hline
\end{tabular}

Figure 2 (a) response shows that $\mathrm{S} / \mathrm{N}$ ratio was maximum for overlap length of $25 \mathrm{~mm}$, adhesive layer thickness of $0.5 \mathrm{~mm}$ and cure temperature of $50^{\circ} \mathrm{C}$. Figure 2 (b) shows main effect plot for 
means and it shows that for overlap length of $20 \mathrm{~mm}$ to $25 \mathrm{~mm}$, there was the increment in joint strength but beyond $25 \mathrm{~mm}$, joint strength drops significantly. It happened due to substrate material failed before joint fails. Increased surface area for adhesion makes joint stiffer than that of the adherend. A similar trend has followed for adhesive layer thickness. In the case of cure temperature, beyond $50^{\circ} \mathrm{C}$, joint got stiffer than the adherend, because for higher curing temperature adhesive strength get increased [15]. It gives the optimum condition for deriving joint strength as overlap length of $25 \mathrm{~mm}$, adhesive layer thickness of $0.5 \mathrm{~mm}$ and cure temperature of $50^{\circ} \mathrm{C}$.

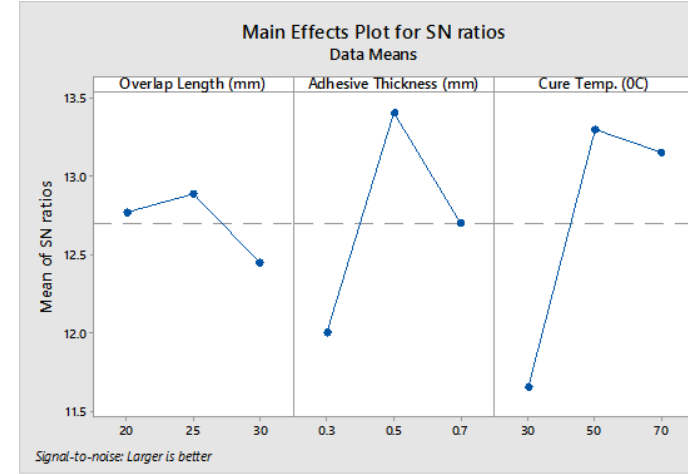

(a)

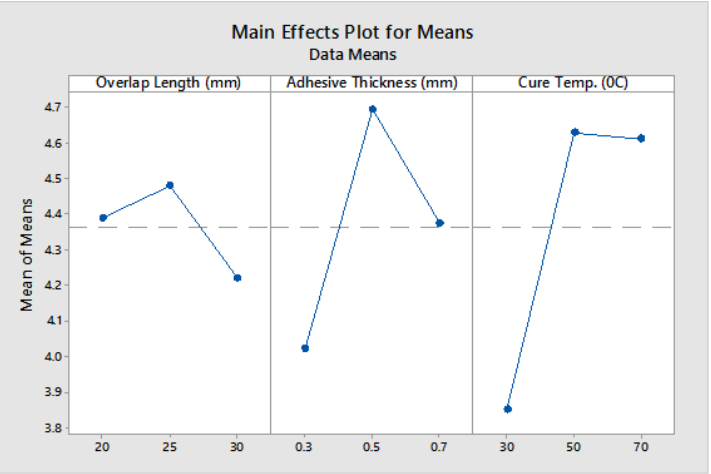

(b)

Figure 2 Main effects plot for $\mathrm{S} / \mathrm{N}$ ratios

Table 4.2 depicts $\mathrm{S} / \mathrm{N}$ ratios for each control factor. The delta value for cure temperature is maximum i.e. difference in highest and lowest values for $\mathrm{S} / \mathrm{N}$ ratio in three level is maximum. This signifies that cure temperature is most influential parameters amongst three; followed by adhesive layer thickness followed by overlap length.

Table 4.2 S/N ratios for each control factor

\begin{tabular}{|l|l|l|l|}
\hline Level & $\begin{array}{l}\text { Overlap } \\
\text { Length }(\mathrm{mm})\end{array}$ & $\begin{array}{l}\text { Adhesive } \\
\text { Thickness } \\
(\mathrm{mm})\end{array}$ & $\begin{array}{l}\text { Cure Temp. } \\
\left({ }^{0} \mathrm{C}\right)\end{array}$ \\
\hline 1 & 12.75 & 12.00 & 11.61 \\
\hline 2 & 12.83 & 13.37 & 13.28 \\
\hline 3 & 12.45 & 12.65 & 13.14 \\
\hline Delta & 0.38 & 1.37 & 1.68 \\
\hline Rank & 3 & 2 & 1 \\
\hline
\end{tabular}

The correlation between the factors and measured joint strength obtained by regression. The empirical relationship between the joint parameters developed was as:

$$
\begin{aligned}
\sigma_{s}=-4.629 & +0.4822 l_{o}-17.98 t_{b}+0.2932 T_{c}-0.007013 l_{0}{ }^{2} \\
& -0.3250 t_{b}{ }^{2}-0.000155 T_{c}{ }^{2}+0.6707 l_{o} \times t_{b}-0.009677 l_{o} \\
& \times T_{c}
\end{aligned}
$$

This empirical relation can be used for predicting tensile strength of adhesively bonded joint in hemp epoxy composites for specified parameters within working range.

\section{CONCLUSION}


This work deals with investigation of influence of joint parameters on tensile strength of adhesively bonded joints in hemp epoxy composites. The composite plate was fabricated by hand lay-up technique. The single-lap joint was created using Fevitite Standard structural grade adhesive. The joints were subjected to uniaxial tensile loading according to ASTM D5868-01. The effect of variation in overlap length, adhesive layer thickness and cure temperature on joint strength was investigated and following conclusions can be derived:

- The statistical analysis reveals that the cure temperature of adhesive is most influencing parameter for joint strength followed by adhesive layer thickness followed by overlap length respectively.

- The statistical analysis reveals optimum condition for obtaining joint strength as overlap length of $25 \mathrm{~mm}$, adhesive layer thickness of $0.5 \mathrm{~mm}$ and cure temperature of $50^{\circ} \mathrm{C}$, which yields joint strength of $4.53 \mathrm{MPa}$.

- The empirical relation developed shows good agreement with experimental results. This relation can be used to derive tensile strength of adhesively bonded joint in hemp epoxy composites for specified parameters within working range.

\section{Nomenclature}

$\mathrm{S} / \mathrm{N} \quad$ Signal to noise ratio

$y \quad$ Average of observed data

$S y^{2}$ Variance of $y$

$n \quad$ Number of observations

$\sigma_{s} \quad$ Tensile shear stress

$l_{o} \quad$ Overlap length

$t_{b} \quad$ Adhesive layer thickness

$T_{c} \quad$ Cure temperature

\section{REFERENCES}

[1] Vaidya U. K., Gautam A. R. S., Hosur M., Dutta P., "Experimental-numerical studies of transverse impact response of adhesively bonded lap joints in composite structures", International Journal of Adhesion \& Adhesives; 26,184-198, 2006

[2] Khalili S.M.R., Khalili S., Pirouzhashemi M.R., Shokuhfar A., Mittal R.K., "Numerical study of lap joints with composite adhesives and composite adherends subjected to in-plane and transverse loads", International Journal of Adhesion \& Adhesives; 28, 411-418, 2008

[3] Avila A. F., Bueno P. O., "An experimental and numerical study on adhesive joints for composites", Composite Structures; 64, 531-537, 2004

[4] Li J., Yan Y., Zhang T., Liang Z., "Experimental study of adhesively bonded CFRP joints subjected to tensile loads", International Journal of Adhesion \& Adhesives; 57, 95-104, 2015

[5] Rahman N. M., Mian A., and Newaz G. M., "Analysis And Characterization Of Adhesively Bonded Mg-Steel Lap Joints", Proceedings of ASME IMEC\&E, Anaheim, California;1-7, 2004

[6] Khalili S.M.R., Shokuhfar A., Hoseini S.D., Bidkhori M., Khalili S., Mittal R.K., "Experimental study of the influence of adhesive reinforcement in lap joints for composite structures subjected to mechanical loads", International Journal of Adhesion \& Adhesives; 28, 436- 444, 2008

[7] Taib A. A., Boukhili R., Achiou S., Gordon S., Boukehili H., "Bonded joints with composite adherends. Part I. Effect of specimen configuration, adhesive thickness, spew fillet and adherends stiffness on fracture", International Journal of Adhesion \& Adhesives; 26, 226 -236, 2006

[8] Campilho R.D.S.G., Moura D.C., Gonçalves D.J.S., "Adhesive joints in natural fibre composites: estimation of fracture properties", Ciência \& Tecnologia dos Materiais; 25, 31-37, 2013 
[9] O’Mahoney D.C., Katnam K.B., O’Dowd N.P., McCarthy C.T., Young T.M., "Taguchi analysis of bonded composite single-lap joints using a combined interface-adhesive damage model", International Journal of Adhesion \& Adhesives; 40, 168-178, 2013

[10] Shahzad A., "Hemp fiber and its composites: A review", Journal of composite materials; $1-14,2011$

[11] Mendoza-Navarro L. E., Diaz-Diaz A., Castaneda-Balderas R., Hunkeler S., Noret R., "Interfacial failure in adhesive joints: Experiments and predictions", International Journal of Adhesion \& Adhesives; 44, 36-47, 2013

[12] Murillo G., Fagan C., Ansell M., Meo M., "Experimental and Finite Element Studies Of Adhesively Bonded Lap Joints for Natural Fibre Composites", $16^{\text {th }}$ International Conference on Composite Materials, Kyoto, Japan; 1-10, 2007

[13] Neto J.A.B.P., Campilho R.D.S.G., da Silva L.F.M., "Parametric study of adhesive joints with composites", International Journal of Adhesion \& Adhesives; 37, 96-101, 2013

[14] Banea M. D. and da Silva L. F. M., "Adhesively bonded joints in composite materials: an overview", Part L: J. Materials: Design and Applications; 223, 1-18, 2008 